\title{
Goal Motives, Well-Being, and Physical Health: Happiness and Self-Realization as Psychological Resources Under Challenge
}

\author{
Paule Miquelon • Robert J. Vallerand
}

Published online: 2 December 2006

(C) Springer Science+Business Media, LLC 2006

\begin{abstract}
An integrative model of goal motives, well-being, and physical health was tested within three studies. Study 1 demonstrated that pursuing autonomous goals was positively associated with both happiness and self-realization, whereas pursuing controlled goals was negatively associated with self-realization, but unrelated to happiness. Study 1 further revealed that self-realization was negatively associated with physical symptoms, whereas happiness was unrelated to the symptoms. Study 2 replicated the findings of Study 1 while showing that academic stress mediated the relationship between self-realization and physical symptoms. Finally, Study 3 replicated the findings of Studies 1 and 2 and additionally demonstrated that academic coping mediated the relationship between self-realization and academic stress. These findings are discussed in terms of their theoretical implications and directions for future research are proposed.
\end{abstract}

Keywords Goal motives · Happiness · Self-realization · Stress $\cdot$ Coping strategies $\cdot$ Physical symptoms $\cdot$ Positive psychology

P. Miquelon

Health Psychology Laboratory, Psychology Department,

McGill University, 1205 Dr. Penfield Avenue,

Montreal (Quebec), Canada H3A 1B1

\section{R. J. Vallerand}

Laboratorie de Recherche sur le Comportement Social, Département de psychologie, Université du Québec à Montréal, Case postale 888, Succursale Centre-Ville, Montréal (Québec), Canada H3C 3P8

e-mail: vallerand.robert_j@uqam.ca

\section{P. Miquelon $(\triangle)$}

Health Psychology Laboratory, Psychology Department,

McGill University, 1205 Dr. Penfield Avenue,

Montreal (Quebec), Canada H3A 1B1

e-mail: paule.miquelon@mcgill.ca
Recent years have seen the rise of the positive psychology approach (Seligman \& Csikszentmihalyi, 2000). This approach focuses on how psychology can best contribute to the adaptive functioning of individuals. Research has thus started to study how optimal psychological functioning and experience (or well-being; Ryan \& Deci, 2001) can contribute to physical health (e.g., Lindfors \& Lundberg, 2002; Pettit, Kline, Gencoz, Gencoz, \& Joiner, 2001). Within this approach, some authors have recently raised the issue as to how different forms of well-being, such as happiness and self-realization, relate to physical health (Ryff, Singer, \& Love, 2004).

In line with this recent concern, the purpose of the present research was to propose and test in three studies an integrative model (see Fig. 1) that examines the nature of mechanisms through which psychological variables influence physical health. ${ }^{1}$ In a nutshell, this model proposes that pursuing goals for autonomous motives facilitates happiness and selfrealization, whereas pursuing goals for controlled motives thwarts these two same forms of well-being. In turn, selfrealization promotes physical health whereas happiness does not. This model and supportive evidence is presented below.

On two forms of well-being: Happiness and self-realization

The present article distinguishes between the hedonic and eudaimonic approaches to well-being, with the former focusing on the outcome of happiness and the latter focusing

\footnotetext{
${ }^{1}$ Throughout this paper, research that has examined the relationship between various variables and physical health will be presented with disregard to physical health's type of indicators (self-report or objective measures) because the findings involving these variables and physical health are similar whether one measures subjective or objective health outcomes. The term "physical health" will thus be used to refer to both objective and self-reported physical health indicators.
} 


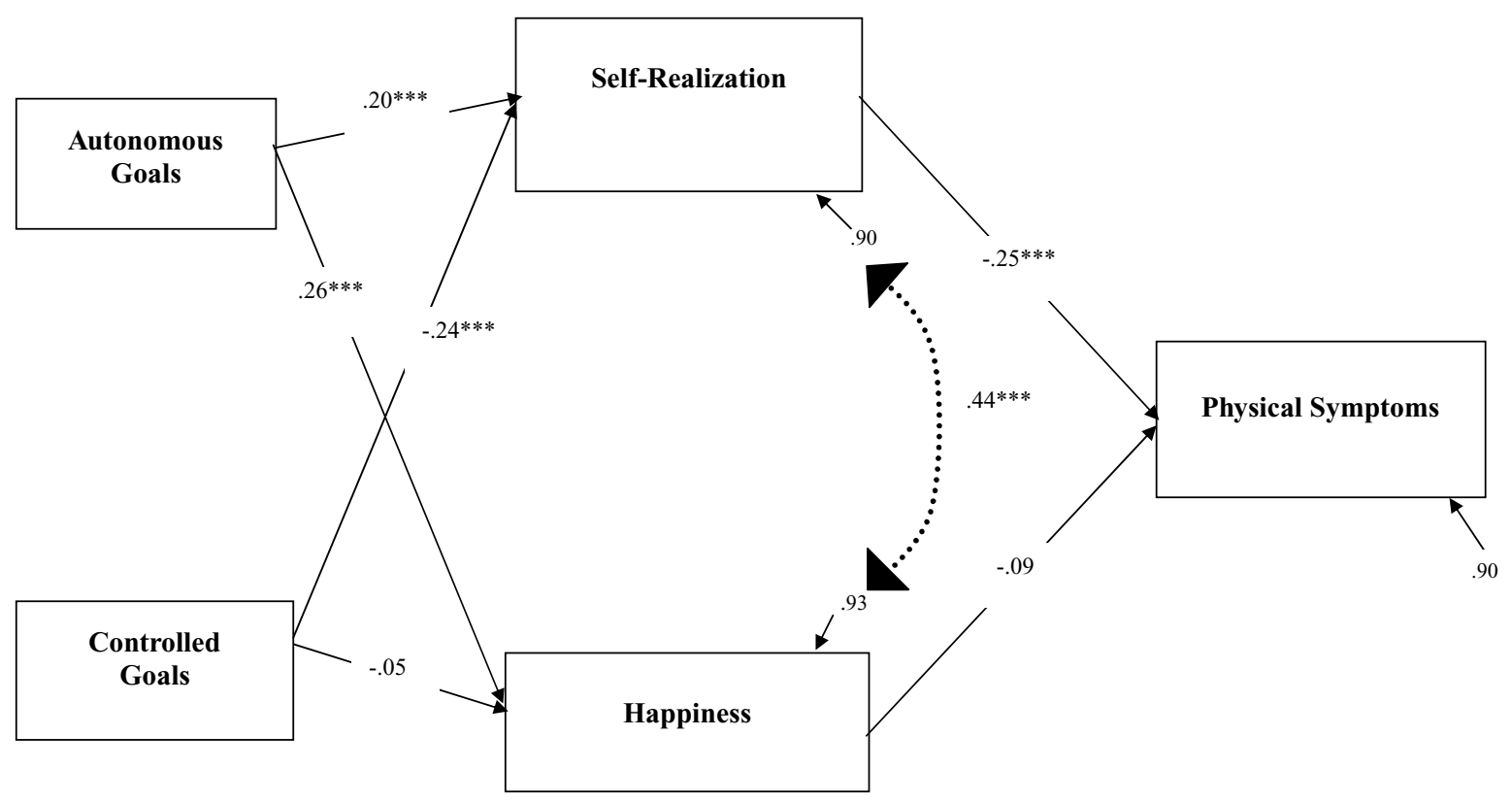

Note. ${ }^{*} p<.05,{ }^{* *} p<.01,{ }^{* * *} p<.001$

Fig. 1 Results from the cross-sectional path analysis: Study 1

not so much on outcomes as on the process of self-realization itself (i.e., the realization of valued human potentials) (see Ryan, Huta, \& Deci, in press).

\section{Happiness}

The hedonic approach defines well-being as the seeking of happiness or pleasure (Ryan \& Deci, 2001). Positive affect (PA) is considered as a central component of happiness (Kahneman, Diener, \& Schwarz, 1999). It reflects pleasurable engagement with the environment and includes the degree to which one feels enthusiastic, alert, and active (Watson, Clark, \& Carey, 1988). In the past, several researchers have used PA to operationalize happiness (e.g., Nix, Ryan, Manly, \& Deci, 1999; Ryff et al., 2004; Steptoe, Wardle, \& Marmot, 2005).

\section{Self-realization}

The eudaimonic approach defines well-being as living a complete human life through seeking the realization of valued human potentials (Ryan \& Deci, 2001). Thus, eudaimonic conceptions focus on the content of one's life and the processes involved in living well. To date, assessments of selfrealization have been multiple but several researchers have used Ryff's Psychological Well-Being framework (PWB; Ryff, 1989; Ryff \& Keyes, 1995) to operationalize it (e.g., Keyes, Shmotkin, \& Ryff, 2002; Lindfors \& Lundberg, 2002). In her PWB scale, Ryff identifies six psychological dimensions of self-realization. Each dimension articulates different challenges individuals encounter as they strive to function positively. These are: self-acceptance (the capacity to see and accept one's strengths and weaknesses); purpose in life (having goals and objectives that give life meaning and direction); personal growth (feeling that personal talents and potential are being realized over time); positive relations with others (having close, valued connections with significant others); environmental mastery (being able to manage the demands of everyday life) and autonomy (having the strength to follow personal convictions, even if they go against conventional wisdom).

\section{Goal motives and well-being}

As will be demonstrated in the later sections in this paper, happiness and self-realization have been found to be differently associated with physical health. It thus appears important to look at the determinants of these two forms of well-being so as to find out which factor can trigger the wellbeing - physical health sequence. With respect to this issue and based on the theory of the basic psychological needs (i.e., autonomy, competence, and relatedness) that are the foundations of well-being (Deci \& Ryan, 2000), Self-Determination Theory (SDT) (Deci \& Ryan, 1985; Ryan \& Deci, 2000) posits that both the content of a goal one pursues and the reasons why it is pursued can influence his or her well-being. Although numerous studies have demonstrated the existence of systematic relations between intrinsic and extrinsic goal contents and well-being outcomes (e.g., Kasser \& Ryan, 1993, 1996), the present article specifically focuses on the 
reasons or motives associated with the goals one pursues and their links with happiness and self-realization. Regarding these reasons or motives, SDT posits that goals can either be pursued out of autonomous (i.e., strong interest or selfidentified personal convictions) or controlled (i.e., internal or external pressures, such as guilt or rewards, respectively) motives. According to SDT, the pursuit of autonomous goals will enhance well-being as these goals are aligned with one's true self, interests, and values, and therefore satisfy the basic psychological needs. Conversely, the pursuit of controlled goals will thwart well-being because these goals do not accurately reflect the interests and values of one's deeper self, and are thus unlikely to satisfy the basic psychological needs.

Numerous researchers have conducted studies examining the motives associated with the goals one pursues and their relation with either happiness (e.g., Sheldon \& Elliot, 1999; Koestner, Lekes, Powers, \& Chicoine, 2002; Sheldon \& Kasser, 1998) or self-realization (e.g., Sheldon, Kasser, Smith, \& Share, 2002). Because all of these studies have assessed goal motives with a relative autonomy score (i.e., subtracting the sum of intrinsic and identified reasons-defined as strong interest and personal convictions, respectivelyfor pursuing goals from the sum of the introjected and external reasons-defined as internal and external pressures, respectively - for pursuing these goals), they do not directly provide empirical evidence on the distinctive relationship between pursuing goals for autonomous and controlled motives and happiness or self-realization. However, Sheldon, Ryan, Deci, and Kasser (2004) have recently demonstrated in three studies that pursuing goals for autonomous motives was consistently positively associated with happiness (as measured by PA and life satisfaction) whereas pursuing goals for controlled motives was negatively, albeit not always significantly, associated with happiness (i.e., controlled goals were unrelated to happiness in Study 1 whereas they were negatively related to PA in Studies 2 and 3). Likewise, as a follow-up to Kasser and Ryan (1993, 1996), Carver and Baird (1998) have demonstrated that pursuing goals for autonomous motives was positively related to self-realization (as measured by self-actualization), whereas pursuing goals for controlled motives was negatively related to this same outcome.

In sum, prior SDT research work on goal pursuit demonstrates that pursuing goals for autonomous motives facilitates happiness and self-realization, whereas pursuing goals for controlled motives tends to undermine these same forms of well-being.

Well-being and physical health

Prior research reveals that happiness (as measured by positive affect) is positively related to physical health, whereas it is negatively associated with illness or physical symp- toms (e.g., Dua, 1994; Pettit et al., 2001; Roysamb, Tambs, Reichborn-Kjennerud, Neale, \& Harris, 2003). Likewise, some researchers have demonstrated that self-realization (as measured by the PWB scale) was positively linked with physical health and negatively associated with a variety of physical symptoms (e.g., Lindfors \& Lundberg, 2002). Past research thus shows that both happiness and self-realization are positively associated with good physical health, but negatively associated with poor physical health. However, such work has not examined the relative impact of happiness and self-realization on physical health. In line with Ryff and her colleagues (2004), we propose that self-realization leads to greater health benefits than happiness because it calls upon a more active and striving organism in the face of existential life challenges. Thus, self-realization should prompt a more adaptive body functioning than happiness and consequently, should foster better physical health. This later assumption is indeed supported by the results of a recent investigation undertaken by Ryff et al. (2004). When examining the relationships between both types of well-being (i.e., happiness and self-realization) and physical health, these authors found numerous significant positive associations between self-realization (as measured by the PWB scale) and various physical health outcomes. However, they found that happiness (as measured by PA) was only positively related to one of these health outcomes. Thus, possessing high levels of self-realization would appear to be more conducive to physical health than high levels of happiness.

\section{The present research}

The goal of the present research was to propose and test in three studies an integrative model that examines the relationships between goal motives (i.e., autonomous versus controlled), happiness, self-realization, and physical symptoms. Study 1 investigated the cross-sectional relation between these variables in order to determine if happiness and self-realization are differently predicted by one's goal motives and can indeed have a distinctive relationship with one's physical health. Studies 2 and 3 sought to replicate the findings of Study 1 and improve upon them by using a prospective design and examining if additional variables, that is coping strategies and stress, serve as a mediators between well-being (i.e., happiness and self-realization) and physical symptoms during a challenging or stressful time for students (i.e., the end of the semester).

\section{Study 1}

The purpose of Study 1 was to test the theoretical model proposed above. Because autonomous goals are aligned with 
one's true self and should satisfy important psychological needs, this model posits that pursuing goals for autonomous motives would be positively associated with both happiness and self-realization. Conversely, this model posits that pursuing goals for controlled motives would be negatively associated with both happiness and self-realization because controlled goals do not accurately reflect the interest and values of one's core self and are unlikely to satisfy important psychological needs. Finally, this model also posits that when both forms of well-being (i.e., happiness and self-realization) are compared simultaneously within the same model (controlling for their common variance), the existing relationship between well-being and physical health should essentially take place through self-realization. In other words, we expected that self-realization (but not happiness) should be negatively and significantly associated with physical symptoms. This last hypothesis is indeed consistent with the assumption that self-realization should lead to greater health benefits than happiness because it entails a more active and striving organism in the face of challenge and thus, should prompt higher body functioning than happiness (Ryff et al., 2004). Thus, as in previous research (e.g., Pettit et al., 2001), a significant and negative correlation between happiness and physical symptoms should be expected, but however, this relationship is anticipated to become null when self-realization is controlled for.

Method

\section{Participants}

308 French-Canadian undergraduate students participated in the study. The sample comprised 222 women and 85 men (1 participant did not specify his or her gender), ranging in age from 19 to 50 years, with a mean of 25 years.

\section{Procedures}

At the beginning of the fall semester 2003, participants completed a questionnaire in class in which they were asked to list three personal goals that they would be pursuing during the semester. This questionnaire also measured goal motives, happiness, self-realization, and physical symptoms. For all participants, the administration of the questionnaire took place three weeks after the beginning of the semester.

\section{Measures}

\section{Personal goals}

To assess personal goals, we used the personal project construct (Little, 1993). The instructions for listing the personal goals were as follows: "Personal goals are projects and con- cerns that people think about, plan for, carry out, and sometimes (though not always) complete or succeed at. They may be more or less difficult to implement; require only a few or a complex series of steps; represent different areas of a person's life; and be more or less time consuming, attractive, and urgent. Please list three personal goals that you have for the semester." These instructions have been originally adapted from the assessment of personal projects (Little, 1993) by Sheldon and Kasser (1998). For each of the three listed goals, academic goals were constantly the most chosen goals compared to any other types of goals (e.g., health, career, interpersonal relationship, or spiritual related goal). These results are not surprising provided that participants were all undergraduate students for whom academic issues represent an important part of their lives.

\section{Goal motives}

To assess these three goal motives, we asked participants to rate their reasons for pursuing each striving in terms of four reasons: external, introjected, identified, and intrinsic. These four reasons sample a continuum of locus of causality for behavior (Ryan \& Connell, 1989), ranging from noninternalized to completely internalized. The external reason was "You pursue this striving because somebody else wants you to or because the situation demands it." The introjected reason was "You pursue this striving because you would feel ashamed, guilty, or anxious if you didn't." The identified reason was "You pursue this striving because you really believe it's an important goal to have." The intrinsic reason was "You pursue this striving because of the fun and enjoyment that it provides you." A 7-point Likert scale, ranging from 0 (Not at all for this reason) to 6 (Completely for this reason) was used. For each participant, we computed an autonomous goals variable by adding the intrinsic and identified items for pursuing the three goals $(\alpha=.51)$. Likewise, we also computed a controlled goals variable by adding the external and introjected reasons for pursuing the three goals $(\alpha=.74)$. This procedure has been used in prior work on goal motives (e.g., Sheldon et al., 2004) and allowed us the advantage of assessing the independent role of pursuing goals for autonomous and controlled motives in well-being.

\section{Happiness}

In line with prior research (e.g., Ryff et al., 2004; Steptoe et al., 2005), happiness was assessed in terms of positive affect. Five positive items from the Positive and Negative Affect Schedule (PANAS; Watson, Clark, \& Tellegen, 1988) were used to measure PA. Participants were asked to rate each item on the basis of how they felt during the past month using a 7-point Likert scale $(\alpha=.77)$, ranging from "Not 
Table 1 Means, standard deviations, and pearson correlations among variables of study $1(N=305)$

\begin{tabular}{llllllll}
\hline Variables & $M$ & $S D$ & 1 & 2 & 3 & 4 & 5 \\
\hline 1. Autonomous goals (1) & 5.10 & 0.88 & 1.00 & & & & \\
2. Controlled goals (2) & 2.70 & 1.24 & .02 & 1.00 & & & \\
3. Happiness (3) & 5.07 & 1.00 & $.26^{* *}$ & -.04 & 1.00 & & \\
4. Self-realization (4) & 5.30 & 0.86 & $.20^{* *}$ & $-.24^{* *}$ & $.51^{* *}$ & 1.00 & \\
5. Physical symptoms (5) & 2.19 & 0.63 & -.07 & $.18^{* *}$ & $-.22^{* *}$ & $-.30^{* *}$ & 1.00 \\
\hline
\end{tabular}

Note. Goal motives (autonomous and controlled) were assessed with a 7-point Likert scale, ranging from "Not at all for this reason" (0) to "Completely for this reason" (0), happiness was assessed with a 7-point Likert scale ranging from "Not at all" (0) to "Extremely" (6), self-realization was assessed with a 7-point Likert scale ranging from "Not agree at all" (0) to "Very strongly agree" (6), and physical symptoms were assessed with a 7-point Likert scale ranging from "Never" (0) to "Almost always" (6).

${ }^{*} p<.05,{ }^{* *} p<.01$.

at all" (0) to "Extremely" (6). A higher score indicated that individuals possessed a higher level of PA.

\section{Self-realization}

In line with past research, self-realization was assessed with the PWB scale (Ryff, 1989; Ryff \& Keyes, 1995). For the sake of the present study, only the short version of the selfacceptance, purpose in life, and personal growth subscales of the PWB was used. This was because the other PWB dimensions (i.e., autonomy, mastery, and relatedness) are closely related to the three basic psychological needs fostering selfdetermined motivation (i.e., autonomy, competence, and relatedness; Ryan \& Deci, 2000) and as such, we felt it was important not to confound them with the basic psychological needs. Moreover, Keyes et al. (2002) have recently demonstrated that it was the existential aspects of the PWB scale (i.e., purpose in life and personal growth) that most cleanly separated self-realization from the affective assessments of happiness. The three subscales used in the present study (i.e., self-acceptance, purpose in life, and personal growth) respectively contained 3,2 and 2 items each, for a total of 7 items ( $\alpha=.71$ ). Participants were asked to rate their agreement with each item on the basis of how they felt about themselves and their lives during the past month, using a 7-point Likert scale ranging from "Not agree at all" (0) to "Very strongly agree" (6). A higher score indicated that individuals possessed a higher level of self-realization.

\section{Physical symptoms}

A symptom checklist consisting of 27 items was adapted from an instrument originally developed by Berne (1995) and revised by Knäuper, Rabiau, Cohen, and Patriciu (2004) to measure physical symptoms. The instrument assesses a comprehensive collection of broad symptoms in a wide variety of areas (e.g., flu-like and stomach ache symptoms). Participants were asked how often they have experienced the 27 symptoms over the past month using a 7-point Likert scale ( $\alpha=.88)$, ranging from "Never" (0) to "Almost always" (6). A higher score indicated that individuals reported more physical symptoms, and thus poorer physical health.

Results and discussion

\section{Preliminary analyses}

Overall, two cases were found to be univariate outliers and 1 case was identified through Mahalanobis distance as a multivariate outlier with $p<.001$ (Tabachnick \& Fidell, 2001). All three outliers were deleted, leaving 305 cases for the analyses. A multivariate analysis of variance (MANOVA) examining gender differences on the overall variables was not significant, Wilks $\lambda, F(5,299)=1.05, \mathrm{p}>.05$. Therefore, all of the analyses reported below are collapsed across sex. Table 1 presents the correlation matrix including all variables.

\section{Path analysis}

The hypothesized model was tested using a path analysis (i.e., a structural model with observed variables) with LISREL 8 (Jöreskog \& Sörbom, 1996). The covariance matrix served as database for the path analysis and the method of estimation was maximum likelihood. A positive covariance was estimated between happiness and self-realization disturbance terms, because these two variables were assumed to positively covary. Results of the path analysis revealed a satisfactory fit of the model to the data. The chi-square value was non-significant, $\chi^{2}(d l=3, N=305)=4.40, p>.05$. However, because the chi-square statistic is sensitive to sample size and model complexity (Sharma, 1996, p. 174), the chi-square ratio, which adjusts for model complexity and sample size, is reported. A chi-square ratio between 1 and 3 typically indicates a good fit (Kline, 1998). The results indicated that the $\chi^{2} /$ df ratio was in an acceptable range $\left(\chi^{2}\right.$ ratio $\left.=1.47\right)$ and other fit indices were relatively high; Non-Normed Fit Index $(\mathrm{NNFI})=.97$, Comparative Fit index 
$(\mathrm{CFI})=.99$, Root Mean Square Error of Approximation $($ RMSEA $)=.039[.000 ; 0.10]$, the Goodness-of-Fit Index $(\mathrm{GFI}=0.99)$, and the Normed Fit Index $(\mathrm{NFI}=0.98)$.

As shown in Fig. 1, with the exception of the estimated path between controlled goals and happiness, all estimated paths were significant. These results provided strong support for the proposed model postulated in Fig. 1. Findings from the path analysis showed that pursuing goals for autonomous motives significantly and positively predicted both happiness and self-realization. In contrast, pursuing goals out of controlled motives significantly and negatively predicted self-realization while it was negatively, but not significantly, associated with happiness. In turn, self-realization was significantly and negatively associated with physical symptoms, whereas happiness was unrelated (i.e., although happiness was negatively associated with physical symptoms, this relationship was not significant) to it. In sum, the findings of Study 1 demonstrated that happiness and self-realization are predicted by different motivational determinants (i.e., autonomous and controlled goals) and are distinctively associated with physical health.

\section{Study 2}

In Study 2, we focused on five important issues that were not addressed in Study 1. The first issue was to understand why self-realization (but not happiness) was found to be negatively linked with physical symptoms. To resolve this issue, we thought it would be worthwhile to examine if happiness and self-realization elicit equivalent inner psychological resources or strengths when one is facing challenges or stressful situations. Indeed, we hypothesized that self-realization is negatively linked with physical symptoms because it triggers greater inner psychological resources than happiness under stress. In other words, we hypothesized that self-realization protects physical health because it entails an active and striving organism in the face of challenge and thus, it enables individuals to react more adaptively under stress. Conversely, we suggested that happiness does not protect physical health because it does not foster action and striving under challenge at the outset and thus, it is less likely to reduce stress. Therefore, our hypothesis was that stress, herein defined as the experience of appraising the demands of a situation as exceeding our available resources to meet these demands (Lazarus \& Folkman, 1984), would mediate the relationship between well-being (i.e., happiness and self-realization) and physical symptoms found in Study 1. Indeed, Ryff et al. (2004) have recently demonstrated that self-realization was associated with lower levels of daily stress whereas happiness was unrelated to it. Moreover, numerous researchers have shown that stress is positively associated with various physical symptoms or health problems (e.g., Cohen et al., 1998; Stone et al., 1992).

A second objective of Study 2 was to use a two-wave prospective design in which the influence of physical symptoms at Time 1 would be controlled for so as to examine if well-being predicts changes in physical symptoms that take place over time. A third objective was to standardize goal content by means of assessing goal motives with respect to only academic goals (consequently, we also adapted our stress measure to the academic context). A fourth objective was to improve our measurement of physical health by adding a self-rated health measure, which represents one of the most reliable indicators of physical health (e.g., Krause \& Jay, 1994), predicting mortality even when known biomedical risks are controlled for (e.g., Idler \& Benyamini, 1997), in addition to a physical symptoms index. Finally, a last objective was to examine the role of neuroticism as a potential confounding variable in the present model. Indeed, past research has shown that neuroticism is positively related to physical symptoms (e.g., Costa \& McCrae, 1987) and stress (e.g., Cimbolic Gunthert, Cohen, \& Armeli, 1999), whereas it is negatively associated with self-rated health (e.g., Benyamini, Idler, Leventhal, \& Leventhal, 2000), happiness (e.g., Diener $\&$ Lucas, 1999), and self-realization (Keyes et al., 2002).

In line with the results of Study 1 and prior research, Study 2 tested a model which posits that: (1) pursuing autonomous academic goals leads to both happiness and self-realization, whereas pursuing controlled academic goals undermine self-realization and (2) self-realization, but not happiness, is negatively associated with academic stress, which, in turn, (3) leads to Time 2 physical symptoms and (4) undermines Time 2 self-rated health. Happiness was expected to be unrelated to stress.

\section{Method}

\section{Participants}

158 French-Canadian undergraduate students participated in the study. The sample comprised 102 women and 44 men (12 participants did not specify their gender), ranging in age from 19 to 53 years, with a mean of 24 years.

\section{Procedures}

Two weeks after the beginning of the winter semester 2004, participants completed a first questionnaire in class. They were asked the following: "Please list three academic goals that you have for the semester." This questionnaire also measured their academic goal motives, their happiness and selfrealization, their neuroticism, their physical symptoms, and their self-rated health. Eleven weeks after they had completed the first questionnaire (i.e., two weeks before the end 
of the semester), participants completed in class a second questionnaire measuring their academic stress, their physical symptoms, and their self-rated health.

\section{Measures}

\section{Academic goals}

The instructions for listing academic goals were the same as in Study 1, except that the term "personal goals" was changed for the expression" academic goals." This change was made because most goals of Study 1 were academic in nature and it allowed us to control for goal content across participants.

\section{Academic goal motives, happiness, and physical symptoms}

We used the same scales as in Study 1 to measure autonomous $(\alpha=.61)$ and controlled $(\alpha=.70)$ academic goals, happiness $(\alpha=.86)$, and Time $1(\alpha=.88)$ and Time $2(\alpha=.90)$ physical symptoms.

\section{Self-realization}

In Study 2, we decided to broaden our measure of PWB. One item was added to each of the PWB subscales that were used in Study 1 (i.e., self-acceptance, personal growth, and purpose in life), for a total of 10 items $(\alpha=.71)$. As in Study 1 , participants were asked to rate their agreement with each item on the basis of how they felt about themselves and their lives during the past month using a 7-point Likert scale ranging from "Not agree at all" (0) to "Very strongly agree" (6).

\section{Neuroticism}

Neuroticism was assessed by a brief measure (Gosling, Rentfrow, \& Swann, 2003) of the NEO Five-Factor Inventory (NEO-FFI; Costa \& McCrae, 1989, 1992) neuroticism's scale. This brief scale includes two items: "I see myself as anxious and easily upset" and "I see my self as calm and emotionally stable" (reversed score). Gosling et al. (2003) have demonstrated that this short scale displays high levels of validity and reliability, roughly equivalent to the full neuroticism subscale of the Big Five Inventory. Respondents rated their agreement with each item on a 7-point Likert scale ranging from "Not agree at all" (1) to "Very strongly agree" (7) $(r(144)=.62, p<.01$ in this study $)$. A higher score indicated greater levels of neuroticism.

\section{Academic stress}

Academic stress was measured with an adapted version of the 10-item Perceived Stress Scale (PSS; Cohen, Kamarck,
\& Mermelstein, 1983) to academic life. Respondents were asked to indicate to what extent they found their "academic life" to be unpredictable and uncontrollable over the last month on a 7-point Likert scale $(\alpha=.87)$ ranging from "Never" (0) to "Always" (6). A higher score indicated that participants experience more academic stress.

\section{Self-rated health}

Self-rated health was measured at both Time 1 and Time 2 with the following item: "In general, how would you rate your physical health during the last month?". Participants rated their overall physical health using a 11-point Likert scale ranging from "Poor" (0) to "Excellent" (10). The higher the score, the better the overall self-rated health. This single item measure of self-rated health has been used in several studies and has been shown to have acceptable psychometric properties (e.g., Krause \& Jay, 1994).

Results and discussion

\section{Preliminary analyses}

Overall, six cases were found to be univariate outliers and 2 cases were identified as multivariate outliers $(p<.001)$. All eight outliers were deleted, leaving 150 cases for the analyses. Furthermore, no sex differences were found $(p>.05)$. Therefore, all of the analyses reported below are collapsed across sex. Table 2 presents the correlation matrix among all variables.

\section{Path analysis}

The hypothesized model was tested using a path analysis with LISREL 8, again using the covariance matrix as database and maximum likelihood as the method of estimation. A positive covariance was estimated between happiness and selfrealization disturbance terms, whereas a negative covariance was estimated between Time 2 physical symptoms and Time 2 self-rated health disturbance terms, provided that these pairs of variables were assumed to covary.

Results of the path analysis revealed a satisfactory fit of the model to the data. Although the estimation of the model revealed that the chi-square value was significant, $\chi^{2}(d l=21$, $N=150)=41.45, p=.005$, the chi-square ratio was in an acceptable range $\left(\chi^{2}\right.$ ratio $\left.=1.97\right)$. Furthermore, the other fit indices were relatively high, $\mathrm{NNFI}=.92, \mathrm{CFI}=.96, \mathrm{RM}$ $\mathrm{SEA}=.08[.034 ; .0 .10]$, GFI $=0.95$, and NFI $=0.93$, therefore indicating adequate model fit (see Kline, 1998). As shown in Fig. 2, the paths obtained supported the predicted hypotheses. First, results replicated the findings of Study 1 with regard to the relationship between academic goal motives (i.e., autonomous and controlled) and the two forms of 
Table 2 Means, standard deviations, and pearson correlations among variables of study $2(N=150)$

\begin{tabular}{|c|c|c|c|c|c|c|c|c|c|c|c|c|}
\hline & $M$ & $S D$ & 1 & 2 & 3 & & 5 & 6 & 7 & 8 & 9 & 10 \\
\hline 1. Autonomous academic goals (1) & 3.89 & 0.87 & 1.00 & & & & & & & & & \\
\hline 2. Controlled academic goals (2) & 1.58 & 1.09 & -.14 & 1.00 & & & & & & & & \\
\hline 3. Happiness (3) & 4.12 & 1.03 & $.29^{* *}$ & -.11 & 1.00 & & & & & & & \\
\hline 4. Self-realization (4) & 4.31 & 0.83 & $.36^{* *}$ & $-.28^{* *}$ & $.64^{* *}$ & 1.00 & & & & & & \\
\hline 5. Time 1 Physical symptoms (5) & 1.17 & 0.72 & $-.16 *$ & $.16 *$ & $-.26^{* *}$ & $-.38^{* *}$ & 1.00 & & & & & \\
\hline 6. Time 1 Self-rated health (6) & 7.26 & 1.72 & $.16^{*}$ & $-.19^{*}$ & $.25^{* *}$ & $.44^{* *}$ & $-.59^{* *}$ & 1.00 & & & & \\
\hline 7. Neuroticism (7) & 2.34 & 1.39 & -.07 & .09 & $-.29^{* *}$ & $-.34^{* *}$ & $.41^{* *}$ & $-.29^{* *}$ & 1.00 & & & \\
\hline 8. Academic stress (8) & 2.53 & 0.84 & -.01 & .15 & -.15 & $-.30^{* *}$ & $.43^{* *}$ & $-.40^{* *}$ & $.34^{* *}$ & 1.00 & & \\
\hline 9. Time 2 Physical symptoms (9) & 1.32 & 0.77 & -.10 & $.19^{*}$ & -.15 & $-.28^{* *}$ & $.62^{*}$ & $-.38^{* *}$ & $.30^{* *}$ & $.43^{* *}$ & 1.00 & \\
\hline 10. Time 2 Self-rated health (10) & 6.58 & 1.72 & .04 & -.02 & $.16^{*}$ & $.17^{*}$ & $-.33^{* *}$ & $.42^{* *}$ & $-.30^{* *}$ & $-.44^{* *}$ & $-.39^{* *}$ & 1.00 \\
\hline
\end{tabular}

Note. Academic goal motives (autonomous and controlled) were assessed with a 7-point Likert scale, ranging from "Not at all for this reason" (0) to "Completely for this reason" (0), happiness was assessed with a 7-point Likert scale ranging from "Not at all" (0) to "Extremely" (6), self-realization was assessed with a 7-point Likert scale ranging from "Not agree at all" (0) to "Very strongly agree" (6), physical symptoms were assessed with a 7-point Likert scale ranging from "Never" (0) to "Almost always" (6), self-rated health was assessed with a 10-point Likert scale ranging from "Poor" (0) to "Excellent" (10), neuroticism was assessed with a 7-point-Likert scale ranging from "Not agree at all" (1) to "Very strongly agree" (7), and academic stress was assessed with a 7-point Likert scale ranging from "Never" (0) to "Always" (6).

${ }^{*} p<.05 ;{ }^{* *} p<.01$.

well-being (i.e., happiness and self-realization). Of major interest is that the present results indicated that academic stress mediated the relationship between self-realization and physical health outcomes. By contrast, happiness was unrelated to academic stress. It thus appears that self-realization, but not happiness, constitutes an important inner psychological resource when it comes to dealing with stressful conditions and thereby preserves one's physical health.

\section{Study 3}

The purpose of Study 3 was to further understand why selfrealization and happiness were found to be differentially related to stress or why they did not elicit equivalent inner psychological resources under challenge. Because coping has been identified as a psychological mechanisms that allows individuals to better deal with stressful situation (Lazarus \& Folkman, 1984), it is likely to think that self-realization, which entails an active and striving organism in the face of challenge, was found to be negatively linked with stress because it sets in motion a more adaptive coping pattern under stressful conditions. Alternatively, it is plausible to suppose that happiness does not supply the individual with an adaptive coping pattern as it entails a more passive approach under stress.

Our hypothesis was thus that coping strategies (i.e., the efforts that people employ to master, tolerate, reduce, or minimize stressful events; Taylor, 1998) would mediate the relationship between happiness and self-realization and academic stress found in Study 2. More specifically, we hypothesized that self-realization would promote more vigilant coping strategies (which represent more proactive and adaptive ways to deal with stressful events; Carver \& Scheier,
1993), which would in turn reduce stress. By contrast, we hypothesized that self-realization would lessen avoidant coping (which represent less adaptive ways to deal with stressful events; Carver \& Scheier, 1993) which would in turn increase stress. Finally, we hypothesized that happiness would not be related to either vigilant or avoidant coping strategies because it would not entail action and striving under challenge at the outset. Although no prior research has examined the relative impact of happiness and self-realization on vigilant and avoidant coping, these hypotheses are in line with prior work that had demonstrated that vigilant coping reduced stress whereas avoidant coping increased stress (e.g., Harnish, Aseltine, \& Gore, 2000).

To be consistent with the academic contextual measures of goal pursuit and stress that were used in Study 2 (i.e., academic goals and academic stress), the model proposed in Study 3 assessed academic coping strategies. In line with the results found in Studies 1 and 2, this model posited that: (1) pursuing academic goals for autonomous motives would be positively associated with both happiness and self-realization, whereas pursuing academic goals for controlled motives would be negatively associated with selfrealization and unrelated to happiness, (2) self-realization would be respectively positively and negatively associated with vigilant and avoidant academic coping, whereas happiness would not be associated with these two forms of academic coping, 3) vigilant and avoidant academic coping would be negatively and positively related to academic stress, respectively, 4) academic stress would be positively associated with Time 2 physical symptoms, but negatively related to Time 2 self-rated health. As in Study 2, this model was tested while controlling for Time 1 physical health indicators (i.e., physical symptoms and self-rated health) and 
Time 1

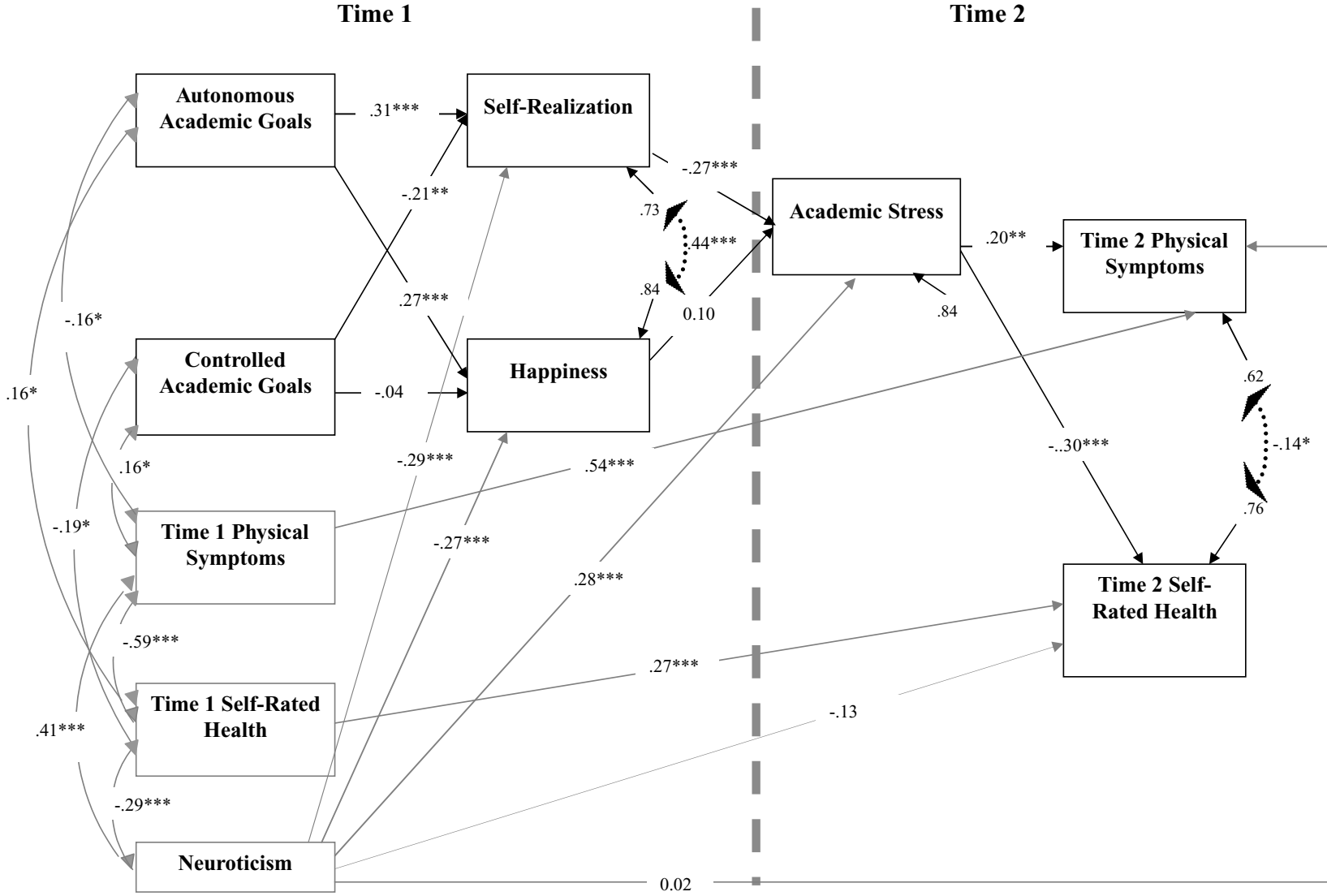

Note. ${ }^{*} p<.05, * * p<.01, * * * p<.001$

Fig. 2 Results from the longitudinal path analysis: Study 2

neuroticism. Finally, because past research had established the existence of a positive relationship between avoidant coping and physical symptoms (e.g., Day \& Livingstone, 2001), this model predicted a positive relationship between avoidant academic coping and Time 2 physical symptoms.

Method

\section{Participants}

240 French-Canadian undergraduate students participated in the study. The sample included 136 women and 55 men (49 participants did not specify their gender) who ranged in age from 19 to 43 years, with a mean of 23 years.

\section{Procedures}

The same procedures as in Study 2 were used to collect the data, with the exception that an additional variable, namely academic coping (vigilant and avoidant), was measured at Time 2. The first questionnaire was completed at the beginning of the fall semester 2004 while the second one was completed at the end of this same semester.
Measures

Academic goals, academic goal motives, happiness, self-realization, academic stress, physical symptoms, self-rated health, and neuroticism

We used the same scales as in Study 1 to measure autonomous $(\alpha=.52)$ and controlled $(\alpha=.74)$ academic goals, selfrealization $(\alpha=.80)$, happiness $(\alpha=.84)$, academic stress $(\alpha=.88)$, Time $1(\alpha=.87)$ and Time $2(\alpha=.90)$ physical symptoms, Time 1 and Time 2 self-rated health, and neuroticism. As in Study 2, a significant correlation was found between the two neuroticism items, $r(229)=.68, p<.01$.

\section{Vigilant and avoidant academic coping}

The short version of the COPE scale (Carver, Scheier, \& Weintraub, 1989) was adapted to assess vigilant and avoidant academic coping. Past research (e.g., Carver et al., 1989; Carver \& Scheier, 1993; Carver et al., 1993) has supported the existence of two principal factors in the COPE; one that can be associated with more vigilant forms of coping (e.g., active coping and acceptance) and one that can be associated 
Table 3 Means, standard deviations, and pearson correlations among variables of study $3(N=229)$

\begin{tabular}{|c|c|c|c|c|c|c|c|c|c|c|c|c|c|c|}
\hline & $M$ & $S D$ & 1 & 2 & 3 & 4 & 5 & 6 & 7 & 8 & 9 & 10 & 11 & 12 \\
\hline 1. Autonomous academic goals (1) & 3.99 & 0.82 & 1.00 & & & & & & & & & & & \\
\hline 2. Controlled academic goals (2) & 1.43 & 1.07 & -.13 & 1.00 & & & & & & & & & & \\
\hline 3. Happiness (3) & 4.19 & 1.02 & $.26^{* *}$ & $-.14^{*}$ & 1.00 & & & & & & & & & \\
\hline 4. Self-realization (4) & 4.33 & 0.86 & $.25^{* *}$ & $-.31^{* *}$ & $.56^{* *}$ & 1.00 & & & & & & & & \\
\hline 5. Time 1 Physical symptoms (5) & 1.14 & 0.69 & -.10 & $.21^{* *}$ & $-.17^{*}$ & $-.22^{* *}$ & 1.00 & & & & & & & \\
\hline 6. Time 1 Self-rated health (6) & 7.3 & 1.68 & .10 & $-.15^{*}$ & $.27^{* *}$ & $.28^{* *}$ & $-.60^{* *}$ & 1.00 & & & & & & \\
\hline 7. Neuroticism (7) & 2.21 & 1.30 & $-.18^{* *}$ & .12 & $-.35^{* *}$ & $-.41^{* *}$ & $.32 * *$ & $-.35^{* *}$ & 1.00 & & & & & \\
\hline 8. Vigilant academic coping (8) & 4.06 & 0.88 & $.17^{*}$ & -.02 & $.15^{*}$ & $.22^{* *}$ & -.09 & .10 & -.10 & 1.00 & & & & \\
\hline 9. Avoidant academic coping (9) & 1.16 & 0.76 & .02 & .09 & -.10 & $-.23^{* *}$ & $.22^{* *}$ & $-.21^{* *}$ & $.21^{* *}$ & $-.20^{* *}$ & 1.00 & & & \\
\hline 10. Academic stress (10) & 2.30 & 0.88 & -.04 & $.18^{*}$ & $-.14^{*}$ & $-.21^{* *}$ & $.29^{* *}$ & $-.21^{* *}$ & $.25^{* *}$ & $-.28^{* *}$ & $.40^{* *}$ & 1.00 & & \\
\hline 11. Time 2 physical symptoms (11) & 1.24 & 0.74 & .05 & $.13^{*}$ & -.09 & $-.14^{*}$ & $.61^{* *}$ & $-.36^{* *}$ & $.29^{* *}$ & -.10 & $.35^{* *}$ & $.42^{* *}$ & 1.00 & \\
\hline 12. Time 2 Self-Rated Health (12) & 6.65 & 1.77 & .05 & -.06 & $.13^{*}$ & .03 & $-.23^{* *}$ & $.31^{* *}$ & $-.21^{* *}$ & $.18^{* *}$ & $-.16^{*}$ & $-.34^{* *}$ & $-.43^{* *}$ & 1.00 \\
\hline
\end{tabular}

Note. Academic goal motives (autonomous and controlled) were assessed with a 7-point Likert scale, ranging from "Not at all for this reason" (0) to "Completely for this reason" (0), happiness was assessed with a 7-point Likert scale ranging from "Not at all" (0) to "Extremely" (6), self-realization was assessed with a 7-point Likert scale ranging from "Not agree at all" (0) to "Very strongly agree" (6), physical symptoms were assessed with a 7-point Likert scale ranging from "Never" (0) to "Almost always" (6), self-rated health was assessed with a 10-point Likert scale ranging from "Poor" (0) to "Excellent" (10), neuroticism was assessed with a 7-point Likert scale ranging from "Not agree at all" (1) to "Very strongly agree" (7), academic stress was assessed with a 7-point Likert scale ranging from "Never" (0) to "Always" (6), and vigilant and avoidant academic coping were assessed with a 7-point Likert scale ranging from "Not agree at all" (0) to "Very strongly agree" (6).

${ }^{*} p<.05 ;{ }^{* *} p<.01$.

with more avoidant forms of coping (e.g., denial, behavioral disengagement, and alcohol/drug use). Respondents rated their agreement with each item on a 7-point Likert scale ranging from "Not agree at all" (0) to "Very strongly agree" (6). To reduce the number of coping dimensions, we entered all coping subscales total scores into a principalcomponents analysis. Two factors with eigenvalues greater than one were clearly interpretable as vigilant and avoidant academic coping. Acceptance and active coping defined the vigilant academic coping factor ( 4 items, $\alpha=.70$ ), whereas denial, self-blame, behavioral disengagement, and substance use defined the avoidant academic coping factor ( 8 items, $\alpha=.74)$.

Results and discussion

\section{Preliminary analyses}

Overall, eight cases were found to be univariate outliers and three cases were identified as multivariate outliers $(p<.001)$. All eleven outliers were deleted, leaving 229 cases for the analyses. Furthermore, no sex differences were found ( $p>.05)$. Therefore, all of the analyses reported below are collapsed across sex. Table 3 presents the correlation matrix involving all variables.

\section{Path analysis}

The hypothesized model was tested using a path analysis with LISREL 8. As in Studies 1 and 2, the covariance matrix served as database for the path analysis and the method of estimation was maximum likelihood. The same covariances as in Study 2 were estimated between pairs of endogenous variables, with the exception that an additional negative covariance was estimated between vigilant and avoidant academic coping disturbance terms. Results of the path analysis revealed a satisfactory fit of the model to the data. The chi-square value was non-significant, $\chi^{2}$ $(d l=36, N=229)=48.87, p>.05$, and the chi-square ratio was in an acceptable range $\left(\chi^{2}\right.$ ratio $\left.=1.36\right)$. Moreover, other fit indices were relatively high, $\mathrm{NNFI}=.97, \mathrm{CFI}=.98$, RMSEA $=.040[.000 ; .0 .066], \mathrm{GFI}=0.97$, and NFI $=0.95$, therefore indicating good model fit. As shown in Fig. 3, the paths obtained supported the predicted hypotheses. The present results again replicated the findings of Studies 1 and 2 with regard to the relationship between academic goal motives (i.e., autonomous and controlled) and the two forms of well-being (i.e., happiness and self-realization). Of main interest, the results of Study 3 indicated that vigilant and avoidant academic coping mediated the relationship between self-realization and academic stress. That is, self-realization positively predicted vigilant academic coping whereas it negatively predicted avoidant academic coping, both of which, in turn, negatively and positively predicted academic stress, respectively. However, happiness was neither associated with vigilant nor with avoidant academic coping. Finally, as expected, academic stress positively predicted physical symptoms whereas it negatively predicted self-rated health.

\section{General discussion}

Our results suggest that individuals who pursue their goals out of strong interest or personal choices (i.e., autonomous goals) have a higher sense of both happiness and selfrealization. In turn, self-realization is negatively associated 


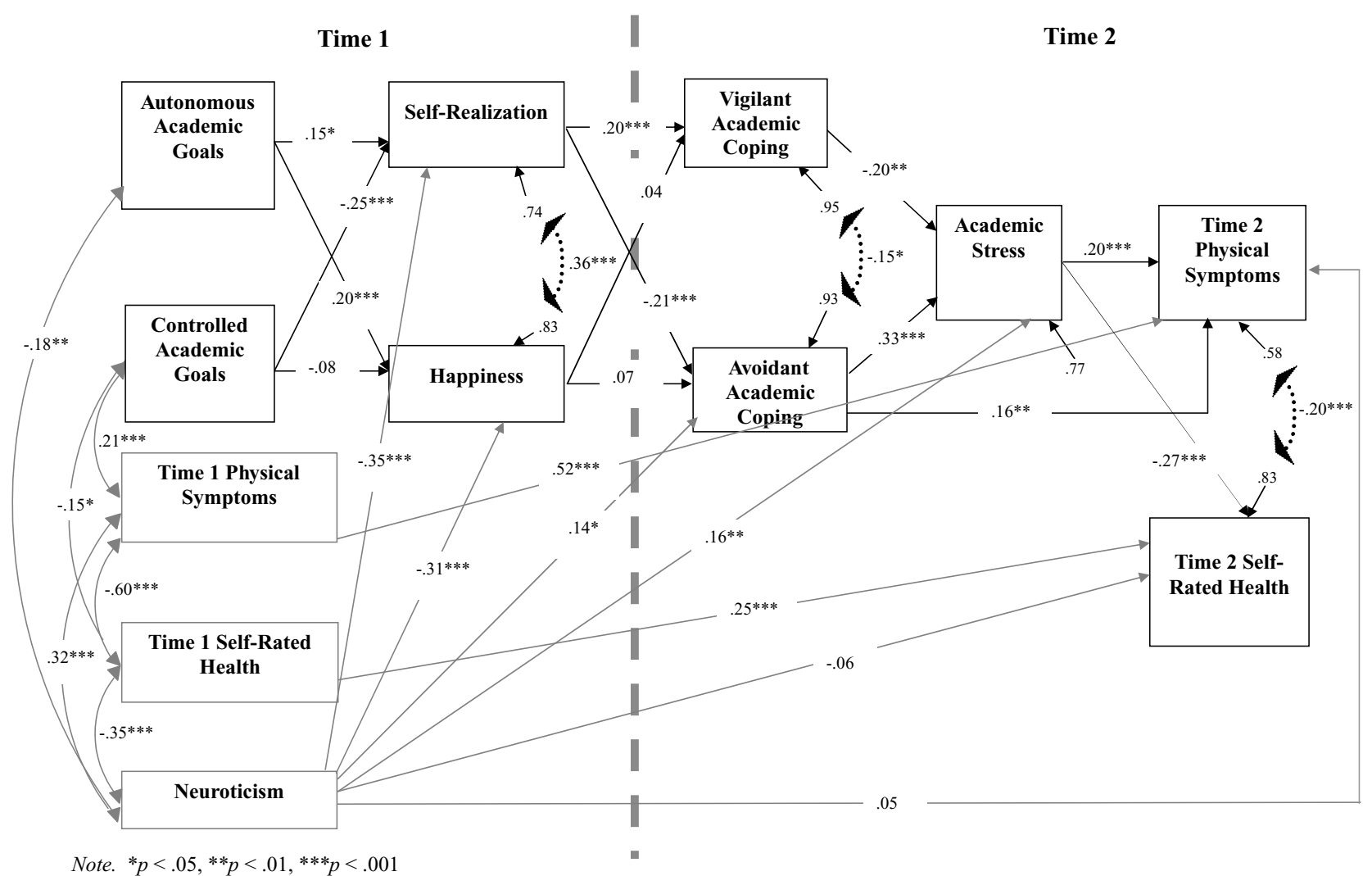

Fig. 3 Results from the longitudinal path analysis: Study 3

with stress because it allows ones to use more adaptive (i.e., vigilant) and less maladaptive (i.e., avoidant) forms of coping. As a result, self-realization (but not happiness) is positively associated with health improvement over the semester. Conversely, individuals who pursue their goals because of internal or external pressures (i.e., controlled goals), have a lower sense of self-realization, but not of happiness. Therefore, these individuals do not have access to a higher sense of purpose and self-realization, which would enable them to experience less stress by means of using more vigilant coping strategies and less avoidant coping strategies. As a result, these individuals' health does not seem to change over the semester. These findings lead to a number of implications that are outlined below.

The relationship between goal motives and well-being

The present findings revealed that pursuing goals out of autonomous motives positively predicts both happiness and self-realization whereas pursuing goals out of controlled motives negatively predicts self-realization but is unrelated to happiness. ${ }^{2}$ Although the non-significant relationship found

\footnotetext{
${ }^{2}$ In the present article, goal motives were examined as predictors of both happiness and self-realization. However, because happiness and
}

between controlled goals and happiness is in fact consistent with findings from certain studies (see Sheldon et al., 2004; Study 1), it is not what we were initially expecting. We however think that this result might originate from the fact that pursuing goals that do not represent people's interests and central values might elicit a mix of positive and negative emotions (e.g., Larsen, McGraw, Mellers, \& Cacioppo, 2004), which would explain the null relationship. For instance, one may feel happy while engaging in non self-actualizing activities (e.g., watching television) but might come to feel disappointed for not having engaged in growth-related activities (e.g., studying or reading).

Overall, our results on the relationship between goal motives and well-being provide support for SDT's views to the effect that only the pursuit of autonomous goals will enhance well-being because they satisfy important psychological needs. The pursuit of controlled goals, however, will

self-realization are broader personality-level variables than goals, a plausible hypothesis would be that happiness and self-realization predict goal motives. This hypothesis was tested with alternative path analysis models for each study. Within each of these models, we used self-realization and happiness as predictors of autonomous and controlled goals. The results revealed that these alternative models were not as adequate as the initial ones, which entails that goal pursuit better predicts well-being than well-being predicts goal pursuit. These analyses are available from the first author. 
not enhance (or may even thwart) well-being because, given that these goals do not accurately reflect the interest and values of ones deeper self, they are unlikely to satisfy important psychological needs (e.g., Deci \& Ryan, 2000; Ryan $\&$ Deci, 2000). Additionally, our results also support prior SDT research work conducted in various settings and cultures. Such work has shown that pursuing goals with an intrinsic content or undertaken an activity for autonomous reasons was positively associated with a variety of both happiness and self-realization related outcomes, whereas pursuing goals with an extrinsic content or doing an activity for controlled reasons was negatively associated with these same wellness indicators (e.g., Kasser \& Ryan, 1993, 1996; Nix et al., 1999; O'Connor \& Vallerand, 1994; Ratelle, Vallerand, Chantal, \& Provencher, 2004; Schmuck, Kasser, \& Ryan, 2000; Vallerand, 1997; Vansteenkiste, Simons, Lens, Sheldon, \& Deci, 2004).

The relationship between well-being and physical health and its mediating processes

The present findings support the existence of a relationship between well-being and physical health. However, they nevertheless underscore that this relationship mainly depends on one specific type of well-being, namely self-realization. By contrast, merely experiencing happiness does not provide any physical health benefits. Indeed, the results of Study 1 demonstrated that self-realization was negatively associated with physical symptoms, whereas happiness was not associated with it. Interestingly, this negative relationship between self-realization and physical symptoms also held when tested with the overall participants of Studies 2 and $3 .^{3}$ Thus, self-realization does predict health improvement that takes place over time. In sum, it appears that when the influence of happiness and self-realization on physical health is simultaneously compared, the existing relationship between well-being and physical health essentially takes place through self-realization. In other words, when controlling for the affect-based aspect of well-being (i.e., happiness), self-realization was found to make an independent contribution to physical health. By contrast, when controlling for self-realization, the affect-based aspect of well-being was not found to make a similar independent contribution to physical health. It would thus appear that the key ingredient within well-being that promotes health is self-realization.

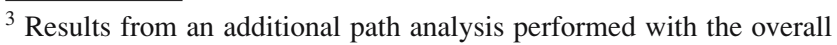
participants of Studies 2 and 3 showed that the initial cross-sectional negative relationship found between self-realization and physical symptoms in Study 1 also existed when a prospective design was used in Studies 2 and 3 . This model revealed a satisfactory fit to the data $\left[\chi^{2}(d l=3, N=379)=4.99, p>.05\right.$, NNFI $=.97, \mathrm{CFI}=.99$, RM$\mathrm{SEA}=.042[.00 ; .10], \mathrm{GFI}=0.99, \mathrm{NFI}=0.98]$ and the findings exactly replicated those of Study 1.
}

The present results also showed that two particular psychological processes, namely coping and stress, can clarify why the two forms of well-being, namely happiness and selfrealization, have a differentiated impact on physical health. Indeed, our results showed that self-realization constitutes a more important inner psychological strength or resource for guarding against stressful events or for coping under challenge than merely being happy (happiness) because it promotes adaptive forms of coping and hinders maladaptive forms of coping under stress or challenge.

In sum, the present paper adds to past research on wellbeing and physical health (e.g., Ryff et al., 2004) because, in addition to demonstrating that happiness and self-realization lead to distinct physical health consequences, it also clarifies the nature of the respective determinants (i.e., autonomous and controlled goals) and mediators of these two forms of well-being. Consequently, the proposed model provides a more comprehensive understanding of the psychological processes through which well-being promotes one's physical health.

\section{Limitations and directions for future research}

Although the present results provided support for the proposed integrative model, some limitations should be taken into consideration when interpreting these findings. First, although a prospective design was used in Studies 2 and 3, it is nevertheless inappropriate to make causal inferences since causality cannot be established with correlational data. Second, the data collected in the present research came from self-report measures. Such measures may be influenced by social desirability biases. Thus, replication with other methods of data collection (e.g., observer ratings and objective health indicators such as biomarkers from diverse physiological systems) would be important. Third, the happiness and self-realization measures that were used in the present paper may present some limitations. Indeed, these measures consisted of short scales and therefore, future research is needed where more elaborated scales (e.g., the full version of the PANAS and PWB scales) are used in order to replicate the present findings. Fourth, the present research has not looked at the role of goal attainment in the relationship between pursuing autonomous and controlled goals on happiness and self-realization. Given that goal attainment has been found to play a role in the relationship between goal pursuit and well-being (e.g., Koestner et al., 2002; Sheldon \& Elliot, 1999), it would be relevant for future research to examine the extent to which it is involved in the association between goal motives and both happiness and self-realization.

Finally, it would be important for future research to explore how happiness and self-realization relate to each other. Indeed, the present research has looked at the unique contribution of happiness and self-realization on physical health 
while controlling for their common variance. However, some researchers have proposed that self-realization is sufficient (albeit not necessary because antecedents of pleasure can also include goals opposing to eudaimonic conceptions, such as living a life of superficial values) pathways to happiness. Stated differently, personal happiness is often contingent on committing oneself to a meaningful life (e.g., Ryff \& Singer, 1998; Waterman, 1993). Alternatively, feeling good (happiness) might also help someone to engage in demanding growth-related activities and thus, to experience self-realization, as suggested by some researchers (e.g., Keyes et al., 2002). Hence, research on the interplay between happiness and self-realization would appear in order.

\section{Conclusion}

Recent efforts in the field of positive psychology have sought to identify personal resources that enable people to lead a better life (Seligman \& Csikszentmihalyi, 2000). The present research contributes to this literature by showing that selfrealization stemming from an eudaimonic lifestyle could represent such a resource, especially as pertains to one's physical health. Additional research is needed, however, in order to provide a more comprehensive picture of the various psychological processes involved in the relationship between well-being and physical health.

Acknowledgments Preparation of this article was facilitated through doctoral fellowships from the Fonds Québécois de la Recherche sur la Société et la Culture (FQRSC) and the Research Council of Canada (SSHRC) to the first author, and through grants from the SSHRC and the FQRSC to the second author.

\section{References}

Benyamini, Y., Idler, E. L., Leventhal, H., \& Leventhal, E. A. (2000). Positive affect and function as influences on self-assessments of health: Expanding our view beyond illness and disability. Journal of Gerontology: Psychological Sciences, 55B, 107-116.

Berne, K. (1995). Running on empty: The complete guide to chronic fatigue syndrome (CFIDS). Alameda, CA: Hunter House Inc.

Carver, C. S., \& Baird, E. (1998). The American dream revisited: Is it what you want or why you want it that matters? Psychological Science, 9, 289-292.

Carver, C. S., \& Scheier, M. F. (1993). Vigilant and avoidant coping in two patient samples. In H. W. Krohne (Ed.), Attention and avoidance: Strategies in coping with aversiveness (pp. 295-320). Seattle: Hogrefe \& Huber.

Carver, C. S., Scheier, M. F., \& Weintraub, J. K. (1989). Assessing coping strategies: A theoretically based approach. Journal of Personality and Social Psychology, 56, 267-283.

Cimbolic Gunthert, K., Cohen, L. H., \& Armeli, S. (1999). The role of neuroticism in daily stress and coping. Journal of Personality and Social Psychology, 77, 1087-1100.
Cohen, S., Frank, E., Doyle, W. J., Skoner, D. P., Rabin, B. S., \& Gwaltney, J. M., Jr. (1998). Types of stressors that increase susceptibility to the common cold in healthy adults. Health Psychology, 17, 214-223.

Cohen, S., Kamarck, T., \& Mermelstein, R. (1983). A global measure of perceived stress. Journal of Health and Social Behavior, 24, 385-396.

Costa, P. T., \& McCrae, R. R. (1987). Neuroticism, somatic complaints, and disease: Is the bark worse than the bite? Journal of Personality, 55, 299-316.

Costa, P. T., \& McCrae, R. R. (1989). NEO/FFI manual supplement. Odessa, FL: Psychological Assessment Resources.

Costa, P. T., \& McCrae, R. R. (1992). Revised NEO personality inventory (NEO-PI-R) and NEO five-factor inventory (NEOFFI) professional manual. Odessa, FL: Psychological Assessment Ressources.

Day, A. L., \& Livingstone, H. A. (2001). Chronic and acute stressors among military personnel: Do coping styles buffer their negative impact on health? Journal of Occupational Health Psychology, 6, 348-360.

Deci, E. L., \& Ryan, R. M. (1985). Intrinsic motivation and selfdetermination in human behavior. New York: Plenum.

Deci E. L., \& Ryan, R. M. (2000). The "what" and "why" of goal pursuit: Human needs and the self-determination of behaviour. Psychological Inquiry, 11, 227-268.

Diener, E., \& Lucas, R. E. (1999). Personality and subjective wellbeing. In D. Kahneman, E. Diener, \& N. Schwarz (Eds.), Wellbeing: The foundations of hedonic psychology (pp. 213-229). New York: Russell-Sage.

Dua, J. K. (1994). Comparative predictive value of attributional style, negative affect, and positive affect in predicting self-reported physical health and psychological health. Journal of Psychosomatic Research, 38, 669-680.

Gosling, S. D., Rentfrow, P. J., \& Swann, W. B., Jr. (2003). A very brief measure of the Big Five personality domains. Journal of Research in Personality, 37, 504-528.

Harnish, J. D., Aseltine, R. H., \& Gore, S. (2000). Resolution of stressful experiences as an indicator of coping effectiveness in young adults: An event history analysis. Journal of Health and Social Behavior, 41, 121-136.

Idler, E. L., \& Benyamini, Y. (1997). Self-rated health and mortality: A review of twenty-seven community studies. Journal of Health and Social Behavior, 38, 21-37.

Jöreskog, K. G., \& Sörbom, D. (1993). LISREL 8: User's reference guide. Chicago: Scientific Software International.

Kahneman, D., Diener, E., \& Schwarz, N. (1999). Well-being: The foundations of hedonic psychology. New York: Russell Sage Foundation.

Kasser, T., \& Ryan, R. M. (1993). A dark side of the American dream: Correlates of financial success as a central life aspiration. Journal of Personality and Social Psychology, 65, 410-422.

Kasser, T., \& Ryan, R. M. (1996). Further examining the American dream: Differential correlates of intrinsic and extrinsic goals. Personality and Social Psychology Bulletin, 22, 280-287.

Keyes, C. L. M., Shmotkin, D., \& Ryff, C. D. (2002). Optimizing well-being: The empirical encounter of two traditions. Journal of Personality and Social Psychology, 82, 1007-1022.

Kline, R. B. (1998). Principles and practices of structural equation modeling. NY: Guilford Press.

Knäuper, B., Rabiau, M., Cohen, O., \& Patriciu, N. (2004). Compensatory health beliefs: Theory and measurement. Psychology and Health, 19, 607-624.

Koestner, R., Lekes, N., Powers, T. A., \& Chicoine, E. (2002). Attaining personal goals: Self-concordance plus implementation intentions equals success. Journal of Personality and Social Psychology, 83, $231-244$ 
Krause, N., \& Jay, G. (1994). What do global health items measure? Medical Care, 9, 930-942.

Larsen, J. T., McGraw, A. P., Mellers, B. A., \& Cacioppo, J. T. (2004). Mixed emotional reactions to disappointing wins and relieving losses. Psychological Science, 15, 325-330.

Lazarus, R. S., \& Folkman, S. (1984). Stress, appraisal, and coping. New York: Springer.

Lindfors, P., \& Lundberg, U. (2002). Is low cortisol release an indicator of positive health? Stress and Health, 18, 153-160.

Little, B. R. (1993). Personal projects and the distributed self: Aspects of a conative psychology. In J. Suls (Ed.), Psychological perspectives on the self (Vol. 4, pp. 157-181). Hillsdale, NJ: Erlbaum.

Nix, G., Ryan, R. M, Manly, J. B., \& Deci, E. L. (1999). Revitalization through self-regulation: The effects of autonomous versus controlled motivation on happiness and vitality. Journal of Experimental Social Psychology, 35, 266-284.

O'Connor, B. P., \& Vallerand, R.J. (1994). Motivation, selfdetermination, and person-environment fit as predictors of psychological adjustment among nursing home residents. Psychology and Aging, 9, 189-194.

Pettit, J. W, Kline, J. P., Gencoz, T, Gencoz, F., \& Joiner, T. E., Jr. (2001). Are happy people healthier? The specific role of positive affect in predicting self-reported health symptoms. Journal of Research in Personality, 35, 521-536.

Ratelle, C. F., Vallerand, R. J., Chantal, Y., \& Provencher, P. J. (2004). Cognitive adaptation and mental health: A motivational analysis. European Journal of Social Psychology, 34, 459476.

Roysamb, E., Tambs, K., Reichborn-Kjennerud, T., Neale, M. C., \& Harris, J. R. (2003). Happiness and health: Environmental and genetic contributions to the relationship between subjective wellbeing, perceived health, and somatic illness. Journal of Personality and Social Psychology, 85, 1136-1146.

Ryan, R. M., \& Connell, J. P. (1989). Perceived locus of causality and internalization: Examining reasons for acting in two domains. Journal of Personality and Social Psychology, 57, 749761.

Ryan R. M., \& Deci E. L. (2000). Self-determination theory and the facilitation of intrinsic motivation, social development, and wellbeing. American Psychologist, 55, 68-78.

Ryan, R. M., \& Deci, E. L. (2001). On happiness and human potentials: A review of research on hedonic and eudaimonic well-being. Annual Review of Psychology, 52, 141-166.

Ryan, R. M., Huta, V., \& Deci, E. L. (in press). Living well: A Selfdetermination theory perspective on eudaimonia. Journal of Happiness.

Ryff, C. D. (1989). Happiness is everything, or is it? Explorations on the meaning of psychological well-being. Journal of Personality and Social Psychology, 57, 1069-1081.

Ryff, C. D., \& Keyes, C. L. M. (1995). The structure of psychological well-being revisited. Journal of Personality and Social Psychology, 69, 719-727.

Ryff, C. D., \& Singer, B. (1998). The contours of positive human health. Psychological Inquiry, 9, 1-28.
Ryff, C. D., Singer, B., \& Love, G. D. (2004). Positive health: Connecting well-being with biology. Philosophical Transactions of the Royal Society of London, 359, 1383-1394.

Schmuck, P., Kasser, T., \& Ryan, R. M. (2000). The relationship of well-being to intrinsic and extrinsic goals in Germany and the U.S. Social Indicators Research, 50, 225-241.

Seligman, M., \& Csikszentmihalyi, M. (2000). Positive psychology: An introduction. American Psychologist, 55, 5-14.

Sharma, S. (1996). Applied multivariate techniques. New-York: Wiley.

Sheldon, K. M., \& Elliot, A. J. (1999). Goal striving, need satisfaction, and longitudinal well-being: The self-concordance model. Journal of Personality and Social Psychology, 76, 482-497.

Sheldon, K. M., \& Kasser, T. (1998). Pursuing personal goals: Skills enable progress, but not all progress is beneficial. Personality and Social Psychology Bulletin, 24, 1319-1331.

Sheldon, K. M., Kasser, T., Smith, K., \& Share, T. (2002). Personal goals and psychological growth: Testing an intervention to enhance goalattainment and personality integration. Journal of Personality, 70, $5-31$.

Sheldon, K. M., Ryan, R. M., Deci, E. L., \& Kasser, T. (2004). The independent effects of goal contents and motives on well-being: It's both what you pursue and why you pursue it. Personality and Social Psychology Bulletin, 30, 475-486.

Steptoe, A., Wardle, J., \& Marmot, M. (2005). Positive affect and health-related neuroendocrine, cardiovascular and inflammatory processes. Proceedings of the National Academy of Sciences USA, $102,6508-6512$.

Stone, A. A., Bovbjerg, D. H., Neale, J. M., Napoli, A., Valdimarsdottir, H., Cox, D., et al. (1992). Development of common cold symptoms following experimental rhinovirus infection is related to prior stressful life events. Behavioral Medicine, 18, 115-120.

Tabachnick, B. G., \& Fidell, L. S. (2001). Using multivariate statistics, 4th edn. Boston: Allyn and Bacon.

Taylor, S. E. (1998). Coping strategies. In D. John \& T. Catherine (Eds.), MacArthur: Research network on socioeconomic status and health. Retrieved December 6, 2004, from http://www. macses.ucsf.edu/Research/Psychosocial/notebook/coping.html.

Vallerand, R. J. (1997). Toward a hierarchical model of intrinsic and extrinsic motivation. In M. P. Zanna (Ed.), Advances in experimental social psychology (pp. 271-360). New York: Academic Press.

Vansteenkiste, M., Simons, J., Lens, W., Sheldon, K. M., \& Deci, E. L. (2004). Motivating learning, performance, and persistence: The synergistic effects of intrinsic goal contents and autonomysupportive contexts. Journal of Personality and Social Psychology, 87, 246-260.

Waterman, A. S. (1993). Two conceptions of happiness: Contrasts of personal expressiveness (eudaimonia) and hedonic enjoyment. Journal of Personality and Social Psychology, 64, 678-691.

Watson, D., Clark, L. A., \& Carey, G. (1988). Positive and negative affectivity and their relation to anxiety and depressive disorders. Journal of Abnormal Psychology, 97, 346-353.

Watson, D., Clark, L. A., \& Tellegen, A. (1988). Development and validation of brief measures of positive and negative affect: The PANAS scales. Journal of Personality and Social Psychology, 54, 1063-1070. 